\title{
Labyrinthe
}

32 | 2009 (1)

Le petit théâtre intellectuel

\section{Le Témoin}

David Schreiber

\section{(2) OpenEdition}

Journals

Édition électronique

URL : http://journals.openedition.org/labyrinthe/3990

DOI : $10.4000 /$ labyrinthe.3990

ISSN : 1950-6031

Éditeur

Hermann

Édition imprimée

Date de publication : 19 juin 2009

Pagination : $59-62$

ISBN : 978-2-7056-6885-3

Référence électronique

David Schreiber, «Le Témoin », Labyrinthe [En ligne], 32 | 2009 (1), mis en ligne le 01 février 2011,

consulté le 20 avril 2019. URL : http://journals.openedition.org/labyrinthe/3990 ; DOI : 10.4000/ labyrinthe.3990

Propriété intellectuelle 


\section{Le petit théâtre intellectuel}

\section{LE TÉMOIN}

Le Témoin, paraît-il, est notre contemporain. Beaucoup le disent et s'en inquiètent. Lui-même ne sait pas encore bien comment remplir son rôle. Non pas qu'il soit novice, mais il avait perdu l'habitude de tant d'attention. Le Spécialiste avait presque triomphé: depuis longtemps il s'était efforcé de le tenir à l'écart, de le mettre sous contrôle. Cruelles confrontations avec ses semblables, interminables tris dans ses propos incohérents, refus d'entendre sa langue propre. Son style même n'avait guère droit de cité : la « mémoire », les « récits », le « vécu », autant de dangers au royaume de la science. Le soupçon sur ses paroles n'était pas seulement permis, c'était la condition même de son droit d'exister. La littérature offrait, certes, un refuge toléré. Encore fallait-il savoir tenir tête aux pourfendeurs de la subjectivité ou savoir attendre avec patience l'âge canonique des Mémoires. Tout le monde ne peut pas se permettre d'écrire à trente ans: "J'ai plus de souvenirs que si j'avais mille ans ».

Certains, à force de travail sur eux-mêmes, avaient semblé un instant pouvoir cumuler les fonctions. L'entreprise avait son charme: par une longue ascèse, ils avaient pu convaincre qu'ils étaient des Observateurs d'un nouveau genre. «L'intellectuel spécifique » semblait même en son temps une figure acceptable. Souvenons-nous d'Edith Rose: « Elle dit: “Tel jour, à tel endroit, j'étais là et j'ai vu; à tel moment, untel m'a dit... et je l'ai entendu; j'ai fait telle demande; voici ce qui me fut répondu par le directeur et j'en porte témoignage sous la foi du serment." Écoutez bien le tremblement de cette voix qui n'hésite plus; c'est une voix singulière et qu'on n'avait jamais entendue aux abords de la prison ». Elle ne prétendait pas pour autant avoir vu « de ses yeux vus, l'homme pieds et mains cloués entre les deux larrons ». Pouvait-elle cependant se passer d'un éloquent Porte-parole? N'avait-elle pas finalement le savoir d'un Expert?

Le Témoin d'aujourd'hui n'est plus de cette espèce. Il se refuse à être une figure composite. Ce dont il témoigne n'est rien d'autre que sa pure expérience et l'indicible est son affaire. Son corps fait sa force, son regard lui suffit. S'il parle, c'est seul. Qu'on n'aille pas chercher à 
expliquer ce qu'il raconte. D'ailleurs y a-t-il seulement une langue pour dire sa singularité? En Victime, il triomphe: l'atrocité, dit-il, est l'horizon indépassable de notre temps. La littérature elle-même n'est plus à ses yeux qu'un gadget inutile.

Le Débatteur enrage. Il n'a que faire de ces êtres muets qui ne savent ni argumenter ni aider à construire la vérité ultime. Le Porte-parole, de son côté, aimerait faire cause commune, porter la plainte : il en connaît d'autres comme lui! Il faut les réunir, faire des associations, faire valoir les droits, exiger des réparations! Mais lui-même, a-t-il seulement le corps? A-t-il le regard? Si par miracle il les possède, on l'écoutera à peine et qu'importe, après tout, qu'ils soient plusieurs dans son cas! Ses compagnons d'infortune, eux-mêmes, n'aiment pas la «politique », l'éthique seule à leurs yeux est digne d'attention. Certains Spécialistes se demandent dès lors s'il ne faut pas revoir la théorie, " changer de paradigme »: « trop longtemps, expliquent-ils, nous avons ignoré ce fondement de l'être social; trop longtemps nous avons douté de nous-mêmes et des autres. Mais comment pourrions-nous vivre sans un minimum de foi et de croyance envers nos semblables? » Des querelles font rage et certains s'interrogent: pour une vérité, combien faut-il de Témoins? Un seul paraît tout de même trop contraire à l'usage...

Mais pourquoi pas? N'est-ce pas au final par lui que tout commence? Que tout arrive? Que tout se dit, et se sait? Laissons-lui peut-être le temps de trouver sa langue, et sûrement, tout doucement, les choses avanceront. Il y a toujours du « commun » dans la langue. C'est le rêve secret du Porte-parole.

À mon tour! Pourquoi pas?

J'ai fait un jour une drôle d'expérience. C'était à une époque un peu triste de ma vie: j'habitais encore la cité, je traînais souvent avec de vieux copains assez peu fréquentables, dans les lieux où l'on traîne. Un jour, dans une gare je crois, j'ai croisé un vieux type, vraiment très vieux, dans les toilettes publiques. Le type m'a parlé. Pour être franc, c'était plutôt rare, à cette époque, que quelqu'un m'adressât la parole comme ça, sans raison, sans avoir peur ou sans vouloir me faire peur, surtout un vieil homme. Il s'est mis à me raconter une histoire de train, pendant la guerre. Il avait été pris par les Allemands. À un moment le train s'est arrêté dans la forêt, quelque part entre l'Allemagne et la 
Pologne. Les déportés ont eu le droit de descendre pour pisser et quand le train est reparti, l'un des leurs n'a pas pu remonter parce qu 'il n'avait pas tout à fait fini. Le vieil homme m'a raconté que tout le monde se marrait de le voir courir comme ça, dans la neige, derrière le train, en tenant son pantalon.

Je raconte ce souvenir parce que plus tard j'ai été amené à travailler avec des gens très sérieux de la télévision, de la radio, de l'université et du ministère de l'Éducation Nationale, sur les archives audiovisuelles du procès de Klaus Barbie. Au procès - et donc sur les images - il y avait de nombreux témoins du même genre. Mais pour la plupart, ils étaient un peu Experts, un peu Porte-parole; le protocole de leurs interventions était parfaitement réglé. Il y avait aussi les avocats des victimes qui répétaient ce que disaient les témoins. Puis, dans le dispositif des émissions, la présentatrice de la télévision qui répétait ce que les avocats répétaient. Et ensuite les universitaires, après la présentatrice, qui expliquaient, en essayant de ne pas répéter, plutôt en ajoutant des choses que les autres avaient oubliées, mal dites, mal comprises. Autour de moi, les gens du ministère insistaient sur le fait qu'il était important de se souvenir de ce que tous ces gens disaient, en répétant le tout de moins en moins clairement. Personnellement, je n'ai pas réussi, tout est sorti de ma tête assez vite. Mais le vieil homme, lui, je ne l'ai pas oublié. Je le vois encore, je l'entends encore, sa voix surtout, son rire.

D. S.

\section{Bibliographie, références, lectures}

I. Deux exemples illustres de « témoignages » littéraires: Henri Barbusse, $L e$ Feu - Journal d'une escouade, Paris, Flammarion, 1916; Primo Levi, Si c'est un homme, Paris, Presses Pocket, 1988 (éd. orig. De Silva, 1947).

II. Michel Foucault, « Discours de Toul », Dits et Écrits, I, Paris, Gallimard, 2001, p. 1105-1106.

III. François Hartog, «Le témoin et l'historien », Gradhiva, 27, 2000, pp. 1-14.

IV. Carlo Ginzburg, Un seul témoin, Paris, Bayard, 2007.

V. Renaud Dulong, Le Témoin oculaire, Les conditions sociales de l'attestation personnelle, Paris, EHESS, 1998.

VI. Paul Ricoeur, La Mémoire, l'histoire, l'oubli, Paris, Le Seuil, 2000. 
Labyrinthe, $n^{\circ} 32$

VII. Vincent Cassel dans La Haine de Mathieu Kassovitz, 1995.

VIII. Ma participation à la réalisation des émissions sur les archives du procès de Klaus Barbie diffusées sur la chaîne histoire en octobre 2000. 